\title{
Study for the development of a photon and gamma shutter for synchrotron accelerators
}

\section{Estudo para desenvolvimento de um bloqueador de fótons e raios-gama para um acelerador síncrotron}

Genivaldo Guska de Sousa ${ }^{1}$, André Augusto², Gabriela de Oliveira Ferigoli², Leonardo Ghizoni ${ }^{2,3}$, Sidney Luiz Alessi Carrara ${ }^{1,2}$, Humberto Pontes Cardoso ${ }^{2}$

\section{ABSTRACT}

This article presents some considerations on the radiation and thermal analyses, as well as the design of the mechanical structure which must actuate the shutter to open and close; releasing or blocking the passage of synchrotron light coming from the particle accelerator. The main goal is to absorb and dissipate the beam energy without using a cooling fluid.

Keywords: Shutter, Photon, Gamma-ray.

\section{RESUMO}

Este artigo apresenta algumas considerações da análise de radiação, análise térmica e o desenvolvimento da estrutura mecânica que deve atuar o bloqueador para abrir e fechar liberando ou bloqueando a passagem do feixe de luz síncrotron vinda do acelerador de partículas. O principal objetivo é absorver e dissipar a energia do feixe sem usar fluido de refrigeração.

Palavras-chave: Bloqueador, Fóton, Raio-gama.

'Faculdade de Tecnologia Prof. Jessen Vidal - São José dos Campos (SP) - Brasil

${ }^{2}$ Equatorial Sistemas S.A. - São José dos Campos (SP) - Brasil

${ }^{3}$ GomSpace A/S - Aalborg - Denmark

Correspondence author: Genival Guska de Sousa - Faculdade de Tecnologia Prof. Jessen Vidal - Av.Cesare Mansueto Giulio Lattes, Eugênio de Melo -12247-014 - São José dos Campos (SP) - Brasil 


\section{INTRODUCTION}

The LNLS (National Synchrotron Light Laboratory) proposed a challenge for the development of a Photon \& Gamma Shutter block for the Sirius program, called SPS - Sirius Photon Shutter ${ }^{(1)}$.

The photon blocker is a safety device because it blocks the beam of radiation emitted by the particle accelerator in a synchrotron light line. The function of the blocker is to dissipate all power by transforming the energy of the beam into thermal energy ${ }^{(2)}$, preventing propagation of the radiation in the line after the closing of the passage of the blocking chamber ${ }^{(1)}$.

The main objective is to develop a compact and efficient system to dissipate all beam energy in the blocker, with a block of density and geometry suitable to withstand the thermal loads. Also, to be able to stop all energy of the incident beam in the assembly, dissipating it without necessity of cooling fluid.

The use of fluid cooling system inside vacuum chamber must to be done with care. Anyleak ofliquid is undesirable because it degrade the vacuum by degassing of water ${ }^{(3)}$ used to cooling the blocker inside the chamber.

This study of doing a shutter without cooling fluid was made in order to verify the possibility of simplify this part of the project, finding innovative way to dissipate heat by radiation ${ }^{(4)}$ from the blocker with the efficiency necessary to meet the project requirements.

\section{MATERIALS AND METHODS}

The blocking occurs in the set of metal blocks in front of the beam. The first block is made of copper $(\mathrm{Cu})$ to dissipate a large thermal load. The second block uses materials such as lead $(\mathrm{Pb})$, pure tungsten (W), or $90 \%$ tungsten alloy, to absorb the radiation produced when electrons undergo deceleration, denominated bremsstrahlung ${ }^{(5)}$.

Based on the requirements received in the Sirius Program documentation and materials properties, the following computational tools (CAD/CAE) were used for the development of the project:

1. GEANT4 to analyze the radiation and to dimension the minimum block size capable of stopping the whole beam power, according to S. Agostinelli at al. ${ }^{(6)}$.

2. SATER 100, a thermal analysis software tool developed by Equatorial Sistemas S/A, to do the thermal analyses ${ }^{(7)}$ and to dimension the minimum block size to dissipate the beam energy.

3. INVENTOR 2010, from Autodesk, to size the mechanical envelope to support parts and vacuum requirements.

\section{RESULTS AND DISCUSSION}

\section{Study of Radiation}

The radiation analysis for Sirius Photon Shutter design includes: a detailed study of the interaction of X-radiation and bremsstrahlung for potential materials and dimensions for the shutter, considering the interaction of radiation with matter and the deflection of the particle in relation to incident direction, where the particle energy loss occurs ${ }^{(8)}$; the material stopping power, among other aspects that will not be approached in this article.

Pure tungsten has a slightly higher stopping power ${ }^{(9)}$ than the others, requiring a length of approximately $18 \mathrm{~cm}$ of material to stop all energy. In order to meet the Laboratory's safety requirements, a block (ingot) with dimensions $10 \mathrm{~cm} \mathrm{x} 10 \mathrm{~cm}$ and a length of $36 \mathrm{~cm}$ was adopted in this study.

Figure 1 presents a comparison of energy loss profiles of different materials, obtained in the simulation for bremsstrahlung with $3 \mathrm{GeV}$ in $\gamma$-ray.

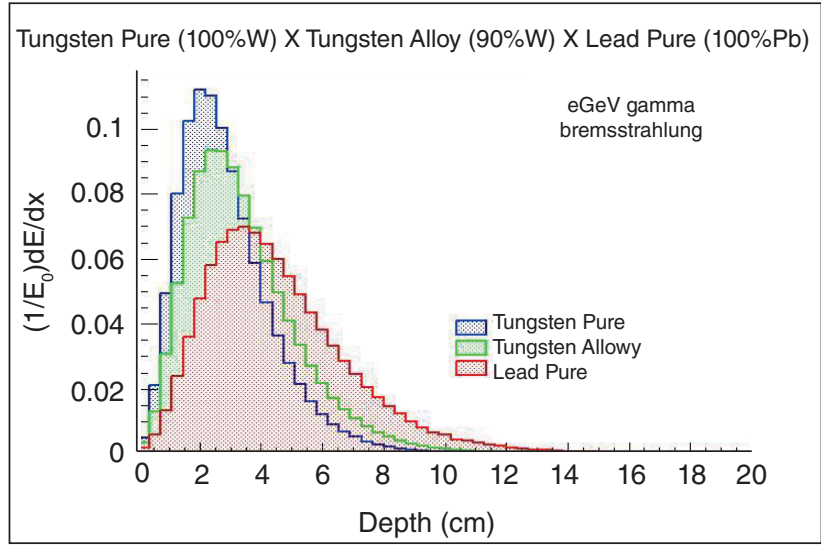

Figure 1: Comparison of energy loss profiles among materials.

Figure 2 presents the copper stopping power simulation to determine the block length as a function of penetration depth of the $\mathrm{x}$-ray beam with $100 \mathrm{keV}$.

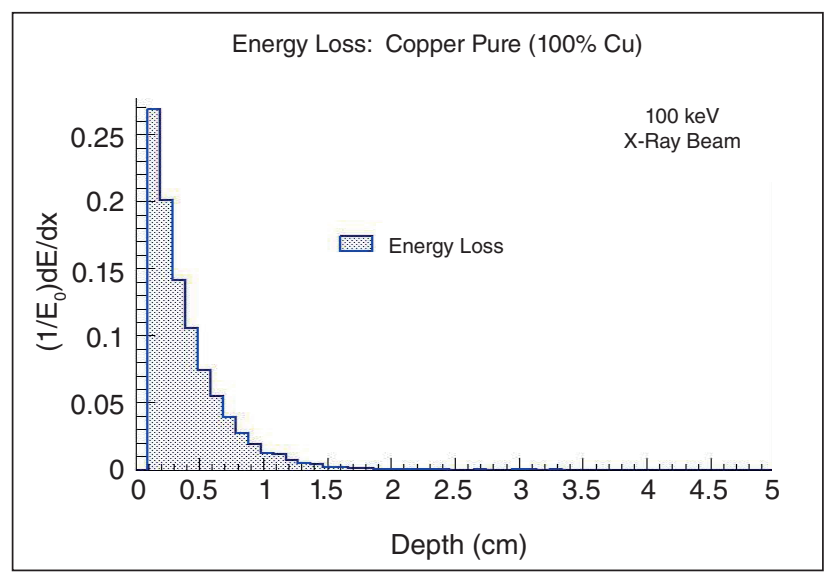

Figure 2: Profile of energy loss of the synchrotron beam in pure copper.

The results indicate that a block $10 \mathrm{~cm}$ wide, $10 \mathrm{~cm}$ high, and $5 \mathrm{~cm}$ long of pure copper is sufficient for the blocking of the synchrotron radiation from the main particle accelerator ring.

In order to stop all energy from the incident beam, it is necessary to combine the two blocks of different materials: the copper blocks the $\mathrm{x}$-rays and the tungsten, the $\gamma$-ray. 


\section{Thermal Study}

Several constructive configurations of the photon blocker were investigated in order to avoid the use of water circulation refrigeration. To do so, solutions were sought that maximized the exchange of heat by radiation between the blocker and the walls of the vacuum chamber, starting from the simplest configuration (ingot only) to configurations using extended surfaces (radiators) ${ }^{(7)}$.

- Configuration - $46 \mathrm{~cm}$ Ingot: Initially the temperature reached by the $46 \mathrm{~cm}$ ingot $(10 \mathrm{~cm} \mathrm{Cu}$ and $36 \mathrm{~cm} \mathrm{~W}$ ) under the specified operating conditions was calculated. The materials' characteristics described in Table 1 were used in the simulations, where $C_{p}$ is the specific heat of the material, $d$, its density, $\varepsilon$, the emissivity, and $k$, the thermal conductivity of the material.

Table 1. Materials' characteristics.

\begin{tabular}{c|c|c|}
\hline Parameter & Copper & Tungsten \\
\hline$C_{p}(\mathrm{~J} / \mathrm{kg} \cdot \mathrm{K})$ & 385 & 130 \\
$d\left(\mathrm{~kg} / \mathrm{m}^{3}\right)$ & 8941 & 19300 \\
$\varepsilon$ & 0.5 & 0.5 \\
$k(\mathrm{~W} / \mathrm{m} \cdot \mathrm{K})$ & 391 & 173 \\
\hline
\end{tabular}

Figure 3 shows the simulation result, with the temperature distribution along the copper block, where the beam is incident, and along the tungsten block. A $200 \mathrm{~W}$ beam applied in the area of $100 \mathrm{~cm}^{2}$ was considered. The external temperature of the vacuum chamber was $48^{\circ} \mathrm{C}$ and its external area was $8756 \mathrm{~cm}^{2}$.

The maximum temperature obtained in the region of incidence of the beam was $263^{\circ} \mathrm{C}$. Although relatively high, it was considered acceptable for this design concept.

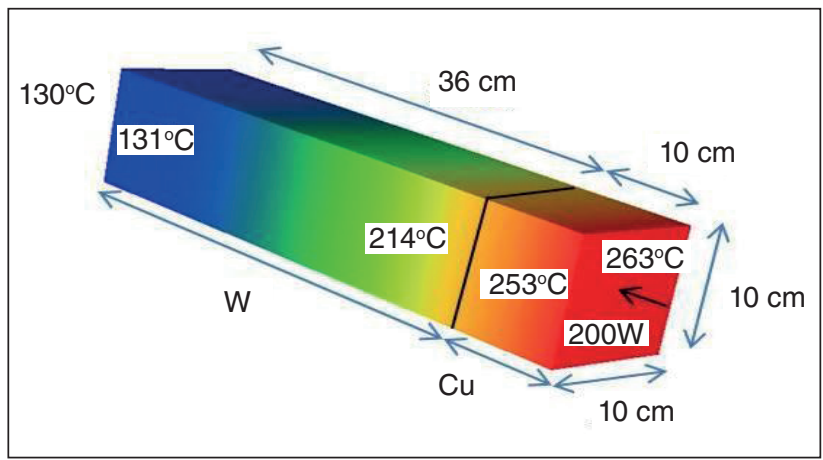

Figure 3: Blocker temperatures in the configuration - Ingot $46 \mathrm{~cm}$.

- Configuration - Ingot $23 \mathrm{~cm}$ : More detailed studies showed that the length of the tungsten ingot could be reduced from $36 \mathrm{~cm}$ to $18 \mathrm{~cm}$. The configuration, as shown in Fig. 4, maintained all the materials' characteristics and parameters of the previous configuration, changing only the length of the copper $(\mathrm{Cu})$ and tungsten $(\mathrm{W})$ blocks.

The new maximum temperature obtained in the region of beam incidence reached $293^{\circ} \mathrm{C}$, which was considered worrying, since a very high temperature requires a more robust thermal insulation between the block and the actuation system, thus increasing the complexity of the project. As a result, it was decided to investigate the possibility of reducing this temperature using a radiator to dissipate heat.

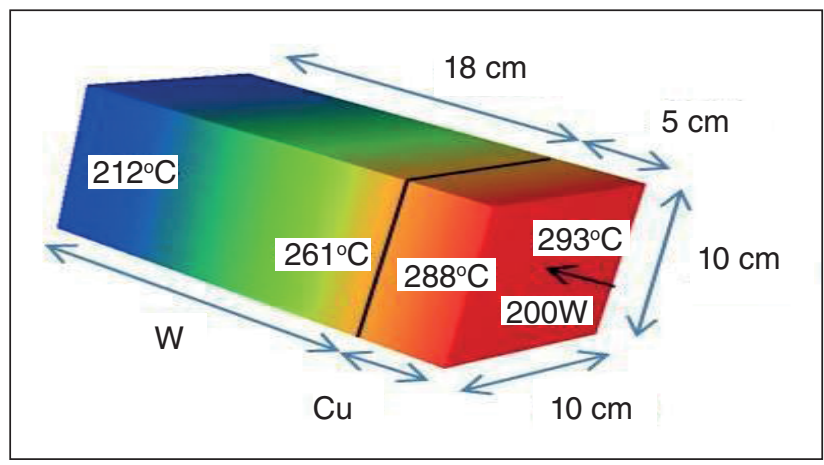

Figure 4: Blocker temperatures in the configuration - Ingot $23 \mathrm{~cm}$.

- $\quad$ Radiator with 40 Fins: The first configuration investigated was a radiator of 40 radial rectangular fins with $0.2 \mathrm{~cm}$ thickness, $18 \mathrm{~cm} \times 5 \mathrm{~cm}$ around the block in the shape of a cup with $10 \mathrm{~cm}$ of diameter and thickness of $0.4 \mathrm{~cm}$, according to Fig. 5. On all surfaces, the emissivity $\varepsilon$ is equal to 0.9 , except on the inner face (B), in contact with the tungsten block.

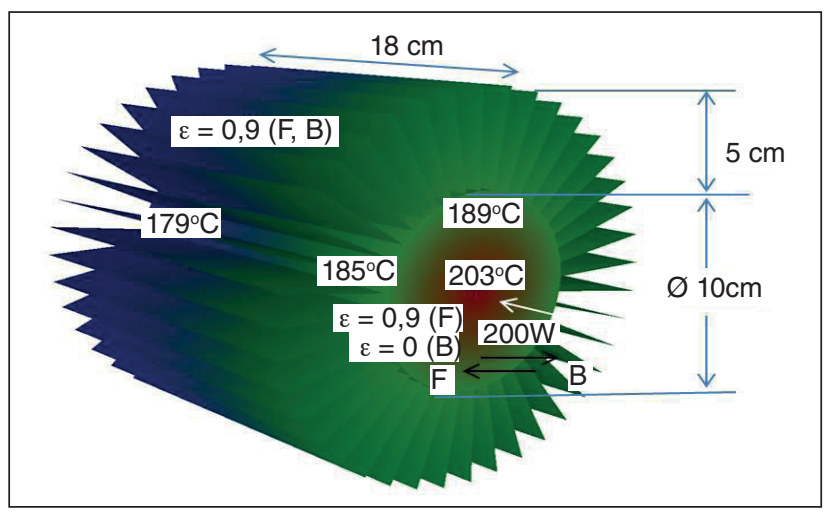

Figure 5: Temperatures of 40-fin radiator.

Although the temperature was reduced to $203^{\circ} \mathrm{C}$ in the region immediately in contact with the center of the blocker, it was considered a very complex configuration to manufacture.

It has also been observed that the small distance between the fins generates a radiation coupling with the very small chamber, due to mutual locking between fins.

- Radiator with 20 Fins: In order to mitigate the problem detected with the previous configuration, the number of radials was reduced from 40 to 20 , without changing its dimensions. With this new configuration, as shown in Fig. 6, the maximum temperature obtained in the region immediately in contact with the center of the blocker was reduced to $184^{\circ} \mathrm{C}$, around $19^{\circ} \mathrm{C}$ below the 40 -fin 
configuration. It was then decided to investigate the possibility of replacing the finned radiator with a cylindrical surface with the same effective area.

- Circular Radiator: The finned radiator was replaced by a cylinder with a $20 \mathrm{~cm}$ outside diameter (without fins), keeping the diameter of the blocker at $10 \mathrm{~cm}$. By varying the diameter of the radiator, several simulations were made, obtaining a lower maximum temperature of $170^{\circ} \mathrm{C}$ for the diameter of $20 \mathrm{~cm}$, as shown in Figure 7.

- Oblong Radiator: Due to the changes introduced by the mechanical design in the radiator configuration and the dimensions of the vacuum chamber, the final model was developed with the shape of an oblong cup, as shown in Fig. 8. It was $20 \mathrm{~cm}$ wide, $12 \mathrm{~cm}$ high, $26 \mathrm{~cm}$ long and $0.5 \mathrm{~cm}$ thick.

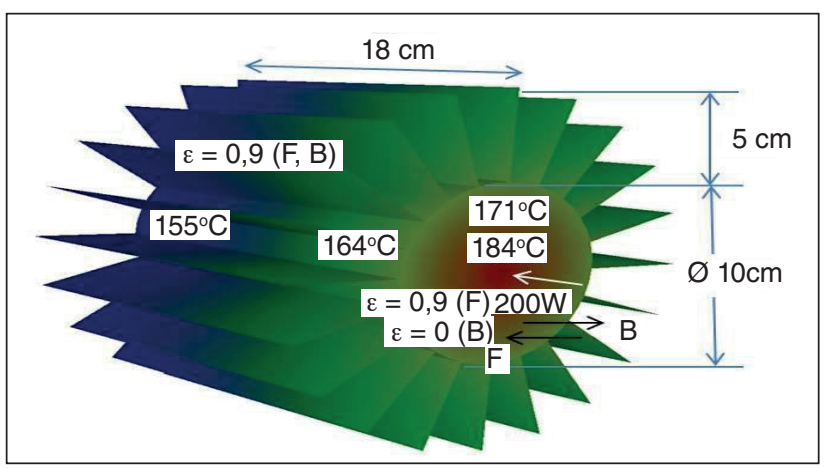

Figure 6: Temperatures of 20 -fin radiator.

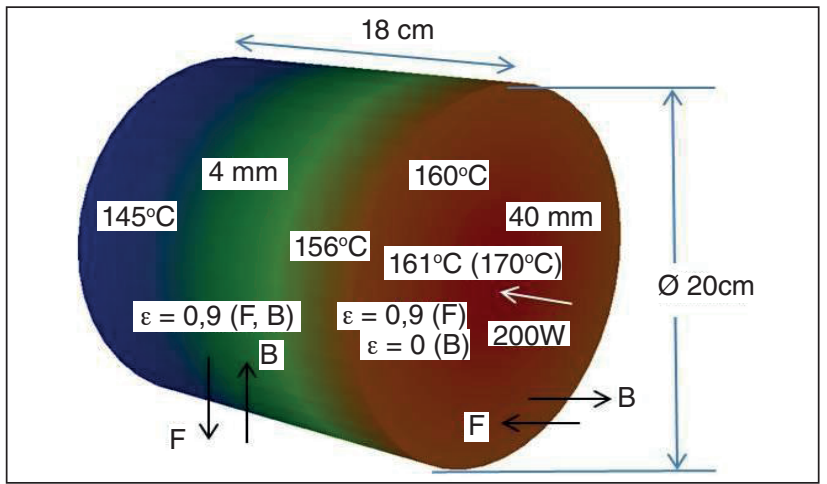

Figure 7: Blocker temperatures with cylindrical radiator (without fins).

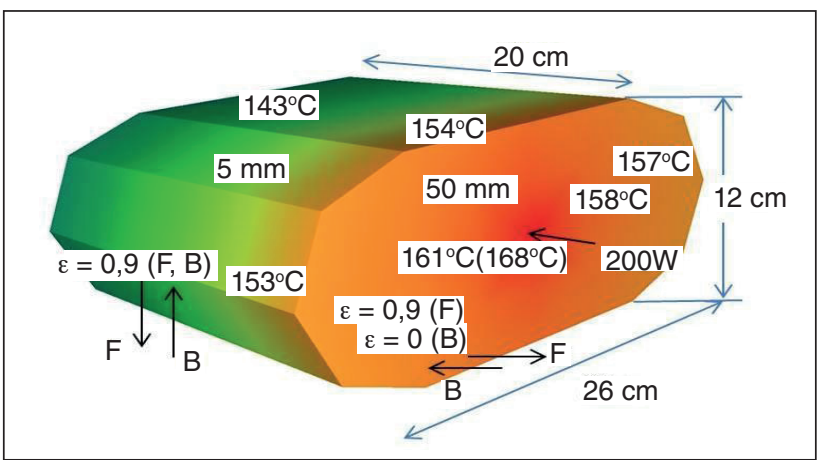

Figure 8: Temperatures of the blocker with an oblong radiator.
Although a much more concentrated beam $(0.3 \mathrm{~cm} \mathrm{x} 0.3 \mathrm{~cm})$ was considered, the maximum temperature obtained was $168^{\circ} \mathrm{C}$, slightly lower than the temperature obtained in the previous configuration.

With oblong geometry, the estimated mean temperature in the walls of the vacuum chamber was $58^{\circ} \mathrm{C}$.

The temperature of $168^{\circ} \mathrm{C}$ was obtained assuming that the emissivity of the internal wall of the vacuum chamber is greater than 0.9. If this value is not attainable, the radiator temperature will increase. For an emissivity of 0.1 , for both the radiator and the inner wall of the vacuum chamber, the blocker temperature reaches values above $450^{\circ} \mathrm{C}$.

\section{Structure Development}

The mechanical design was developed simultaneously with the radiation and thermal studies. The mechanical concept was started considering the LNLS requirements, and reiterated with feedback from the results of the radiation and thermal analyses.

The first configuration of the vacuum chamber with $35.56 \mathrm{~cm}$ (14 inches) of nominal diameter and $70 \mathrm{~cm}$ length, as shown in Fig. 9, used a cylindrical copper block $(\mathrm{Cu})$ of $13.7 \mathrm{~kg}$ with dimensions $\varnothing 14 \mathrm{~cm} \times 10 \mathrm{~cm}$ and a tungsten block (W) of $107 \mathrm{~kg}$ with dimensions $\varnothing 14 \mathrm{~cm}$ x $36 \mathrm{~cm}$. The area of the $10 \mathrm{~cm} \times 10 \mathrm{~cm}$ square is circumscribed in the $14 \mathrm{~cm}$ diameter circumference.

The mass of the set with the $\mathrm{Cu}-\mathrm{W}$ blocks is $121 \mathrm{~kg}$. At least two support points are necessary for lifting and positioning the blocker.

With the advancement of radiation and thermal studies, a leaner design was developed, reducing the size of the vacuum chamber because the mass of the blocker was reduced.

To reduce the assembly's temperature, it was necessary to develop an integral radiator to the copper block $(\mathrm{Cu})$ with an approximate total area of $1885 \mathrm{~cm}^{2}$ of external surfaces, as shown in Fig. 10.

The thermal analysis of the Circular Radiator presents a reduction in the maximum temperature in relation to the

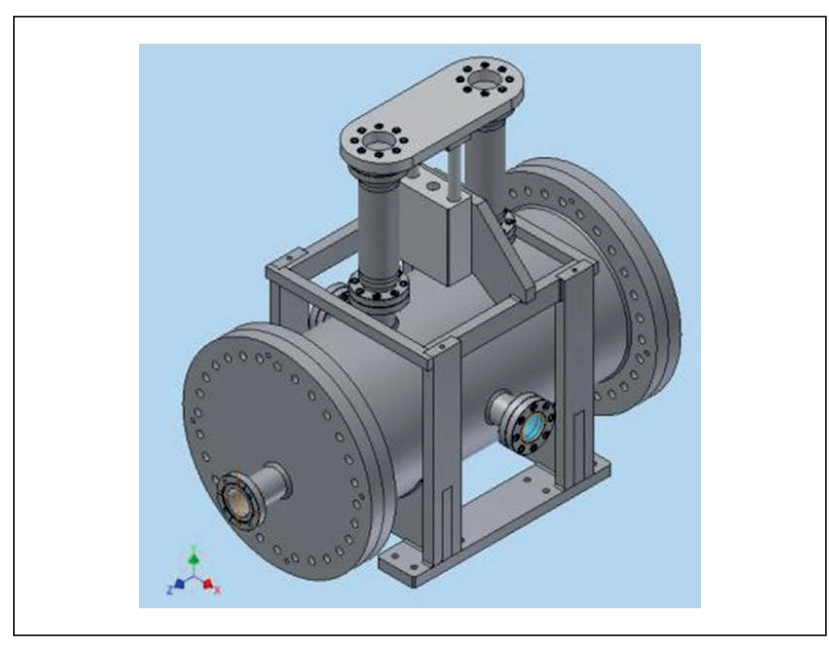

Figure 9: Vacuum Chamber of $\varnothing 35.56 \mathrm{~cm} \times 70 \mathrm{~cm}$. 
previous ones. To accommodate the radiator without increasing the volume of the vacuum chamber, the radiator was changed to the oblong profile, as shown in Fig. 11, with a total surface area of approximately $1924 \mathrm{~cm}^{2}$. This was slightly larger than the circular profile.

Radiation and thermal analyses allowed the reduction of the length and diameter of the blocker. With this, the vacuum chamber can be reduced from $70 \mathrm{~cm}$ to $50 \mathrm{~cm}$ in length and the nominal diameter reduced from $35.56 \mathrm{~cm}$ (14 inches) to $30.48 \mathrm{~cm}$ (12 inches). The weight reduction was significant due to the high density of tungsten, making it possible to use only a fulcrum for the pneumatic actuator, as shown in Fig. 12.

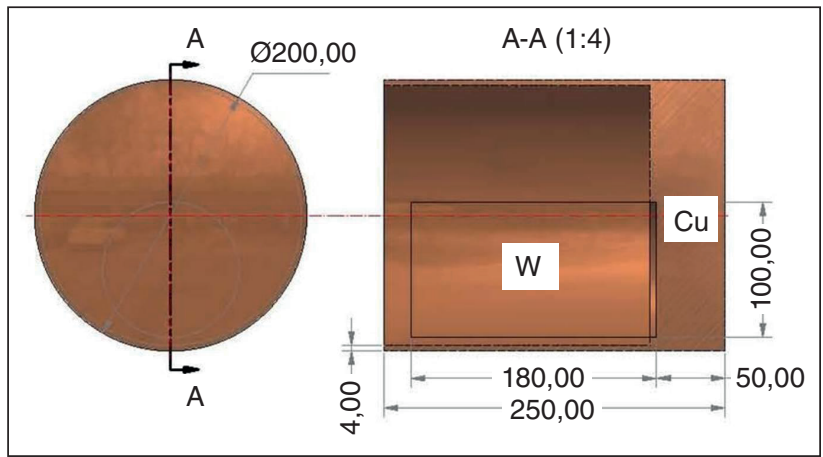

Figure 10: Radiator with circular profile.

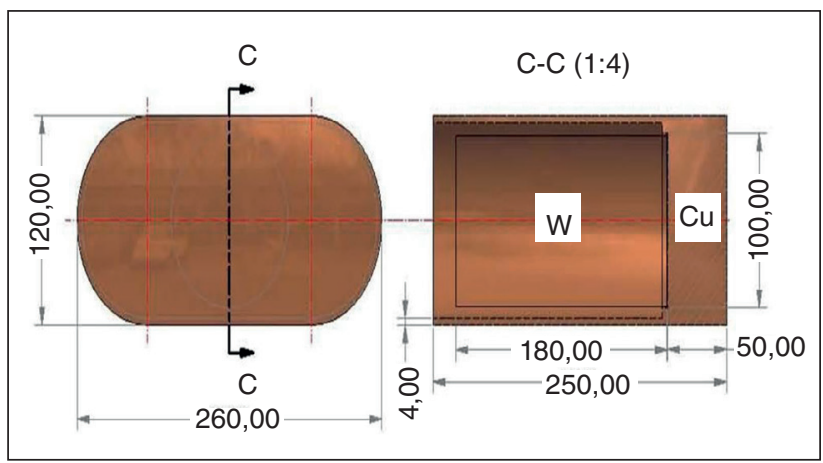

Figure 11: Radiator with oblong profile.

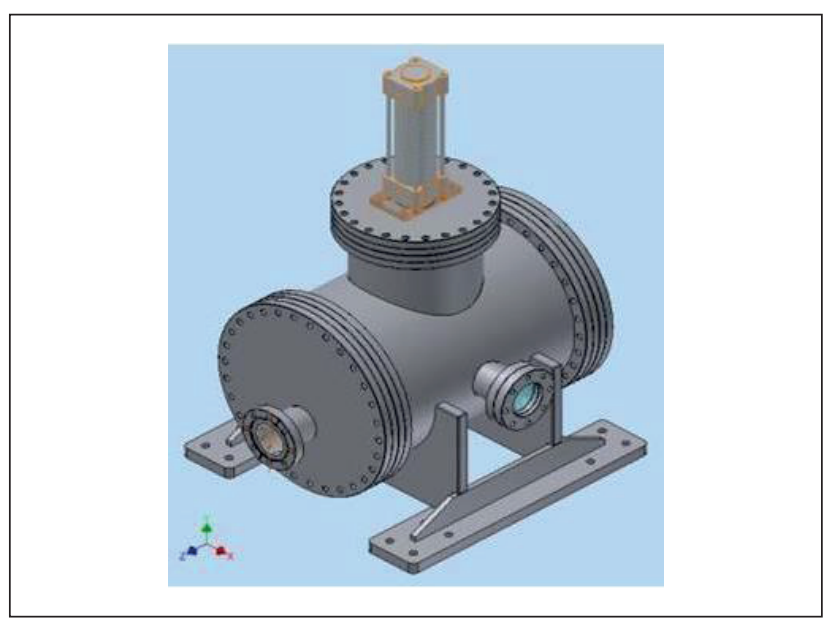

Figure 12: Vacuum chamber $\varnothing 30, .48 \mathrm{~cm} \times 40 \mathrm{~cm}$ with only one pneumatic actuator.

\section{CONCLUSION}

The development of this design was based on the study of thermal dissipation only by radiation, without considering convection and conduction of heat, since the blocker works in an ultra-high vacuum environment. The initial intention was to dissipate all energy by thermal radiation while maintaining the blocker at an acceptable temperature during operation, without the need to add a refrigerant circuit inside the vacuum chamber.

The results showed that, with the use of high emissivity coatings ( $\varepsilon>0.9$ ) inside the vacuum chamber, the blocker temperature will be kept below $170^{\circ} \mathrm{C}$, which was considered acceptable during operation. However, coatings with high emissivity are usually incompatible with ultra-high vacuum. Polished surfaces, normally used in these chambers, have emissivity well below 0.1 , raising the temperature above $450^{\circ} \mathrm{C}$.

The challenge presented here is to identify processes that provide surface finishes of high emissivity in the infrared spectrum, which are economically and compatible with ultra-high vacuum environments.

\section{ACKNOWLEGMENTS}

This project was supported by FAPESP/FINEP process number: 2014/50786-3.

\section{REFERENCE}

1. FAPESP e MCTI/FINEP/FNDCT, Seleção Pública, Propostas para Inovação, Desafios: 13 - Gamma Shutter e 14 - Photon Shutter PAPPE-PIPEIII, 2014. http://www.fapesp.br/chamadas/2014/ Chamada_PAPPE_LNLS_Sirius_anex01.pdf

2. GEBHART, B., Heat Transfer; McGraw-Hill, 1971

3. GEROLA, A. P. et al., Determinação da Entalpia de Vaporização de Líquidos pelo Método do Isoteniscópio de Smith e Menzies, Química Nova, v. 33, n. 2, p. 482-488, 2010. http://ref.scielo.org/ w9pf8k

4. SPARROW, E.M. and CESS, R.D.; Radiation Heat Transfer McGraw-Hill, 1978

5. BERGER, M. J. et al., Stopping Power and Range Tables for Electrons, Protons and Helium Ions, NIST, 2005. http://physics. nist.gov/PhysRefData/Star/Text/contents.html

6. AGOSTINELLI, S. et al., "Geant4 - A Simulation Toolkit", Nuclear Instruments and Methods A 506: 250-303, 2003. http://dx.doi. org/10.1016/S0168-9002(03)01368-8

7. GILMORE, D. G., Satellite Thermal Control Handbook; The Aerospace Corporation Press, Chapter 6: 209; Chapter 15: 234251, 1994.

8. LEO, W. R., Techniques for Nuclear and Particle Physics Experiments, Springer-Verlag, 2nd Revised Edition, ISBN 0-38757280-5 Section 2.7.4: 59-61, 1994.

9. SIGMUND, P. et al., Stopping of Ions Heavier than Helium (REPORT 73), International Commission on Radiation Units \& Measurements, ICRU, 2005 http://www.icru.org/home/reports/ stopping-of-ions-heavier-than-helium-report-73 